\title{
On the Cover of this Issue: Analysis of Shot Peening Particle Stream Using Particle Tracking and Digital Image Correlation by R.F. Kubler, R. Rotinat, J. Badreddine, and Q. Puydt
}

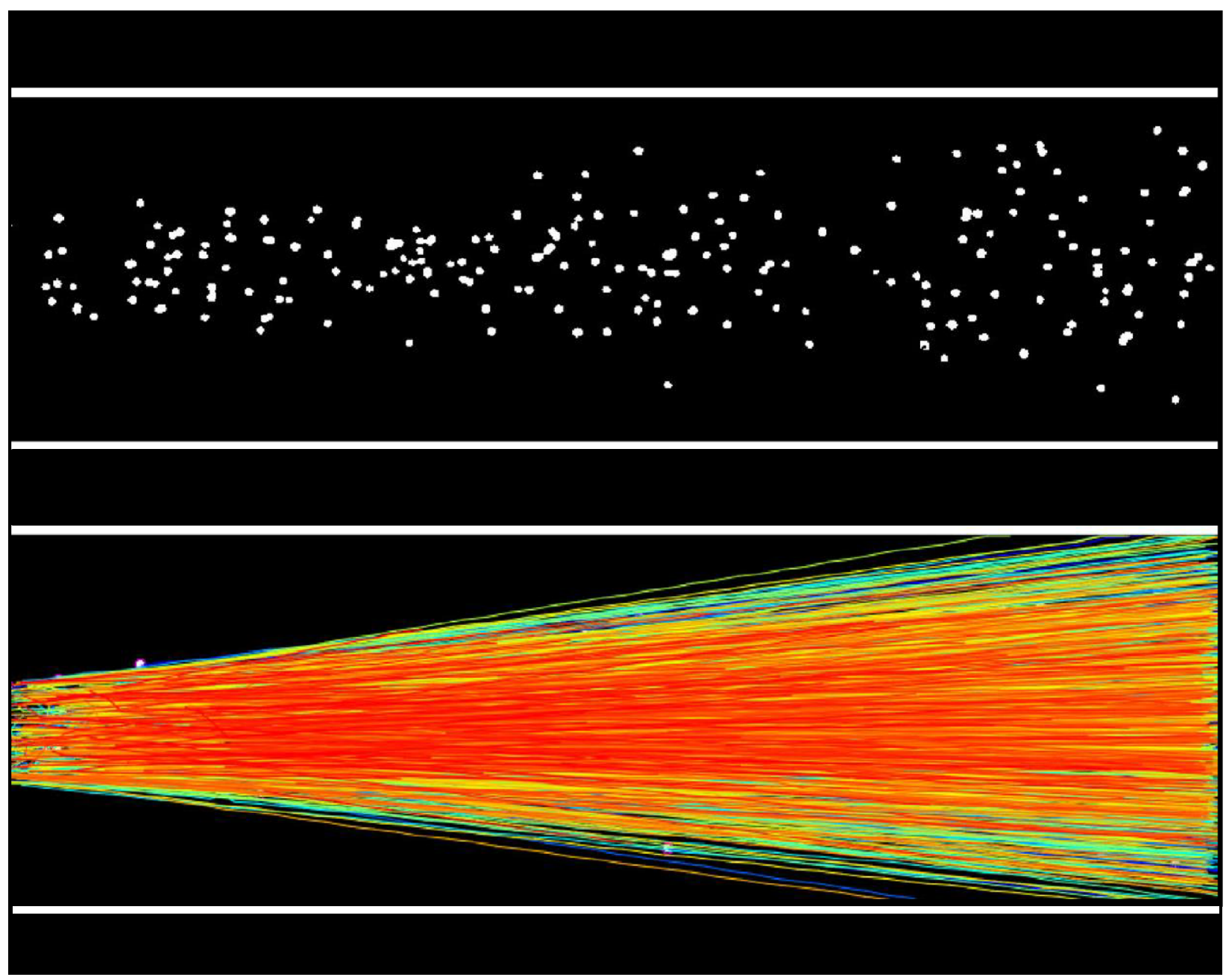

Analysis of Shot Peening Particle Stream Using Particle Tracking and Digital Image Correlation by R.F. Kubler, R. Rotinat, J. Badreddine, and Q. Puydt 